\title{
The Soifer (formerly Colorado) Mathematical Olympiad, why it was founded, bridge between its problems and mathematics, and lives of its winners: an essay
}

\author{
Alexander Soifer ${ }^{1}$ \\ Accepted: 12 November 2021 / Published online: 3 January 2022 \\ (c) FIZ Karlsruhe 2021
}

\begin{abstract}
Mathematics, rightly viewed, possesses not only truth, but supreme beauty... capable of a stern perfection such as only the greatest art can show.

-Bertrand Russell

Beauty is an instance which plainly shows that culture is not simply utilitarian in its aims, for the lack of beauty is a thing we cannot tolerate in civilization. -Sigmund Freud, 1930
\end{abstract}

\section{Part I. Why was the Colorado Mathematical Olympiad created?}

I created the Colorado Mathematical Olympiad in the style of Olympiads in which I competed as a middle and high school student, or was a member of the Olympiad's Jury, in the Moscow Mathematical Olympiad and Soviet Union National Mathematical Olympiads. In the reference list, you will find many fine problem books of Moscow, Russian, and Soviet Union Mathematical Olympiads (Agahanov et al., 2007; Fedorov et al., 2006; Gal'perin \& Tolpygo, 1986; Leman, 1965; Shklarsky et al., 1994; Tolpygo, 2010; Vasiliev \& Egorov, 1988). However, there is one fundamental distinction.

Russian Olympiads offered separate Olympiads for each school grade. We offer the same 5 problems and $4 \mathrm{~h}$ to solve them to everyone who comes, usually students of grades 6 through 12. Consequenctly, Russian and other national Olympiads, and the International Olympiad, expect and test much of the relevant knowledge. Our problems require practically no knowledge - they reward ingenuity, creativity, and originality of thinking of our young Olympians.

Alexander Soifer

asoifer@uccs.edu

1 University of Colorado Colorado Springs, Colorado Springs, USA
I have often been asked: what are Mathematical Olympiads for? I gave complete answers in my three books dedicated to the history of the Olympiad, its problems and solutions, and further explorations (Soifer, 1994, 2011, 2017). By nature of the genre, I will be much more concise here. There are several reasons for creating Olympiads. Someone created mathematical Olympiads for me; it is now my turn to create Olympiads for the next generations. Every Olympiad is a contribution to the longevity of the profession, to passing the mathematical baton. It is also my 'thank you' to the United States and the State of Colorado, which enabled me to live my version of an American dream. And it is an attempt to recognize best young mathematicians-and to not limit recognition of young talents to footballers alone.

Do Olympiads predict who will go far in mathematics and who will not? There is no way to do well by accident, by luck, in an Olympiad, which is an essay-type competition, requiring presentation of complete solutions. Therefore, those who even sometimes have done well in Olympiads, undoubtedly have talent. Does it mean they will succeed in mathematics? As the great Austrian writer Hugo von Hofmannsthal put it in 1922, Talent is not performance; arms and legs are no dance. With talent, it still takes work, hard work, to succeed. I would say talent imposes an obligation on its owner, a duty not to waste the talent. I must add, nothing is a guarantee of success, life interferes, throws barriers in the way. It is critical to know in your gut that in order to succeed no reason for failure should be acceptable.

The inverse here is not true. Those who have not done well in Olympiads do not necessarily lack talent. They may be late bloomers: Einstein comes to mind. Their talent may be in another field or activity. I believe there are no talentless people- there are people who have not identified their talent and thus have not developed it.

In addition to allowing talents to shine, Olympiads introduce youngsters to the kind of mathematics they may have not seen in school. It was certainly the case with me. Olympiads showed me the existence of mathematics that justifies 
such adjectives as beautiful, elegant, humorous, defying intuition. Olympiad-type mathematics inspires and recruits mathematicians of the future.

And one more thing. The students who do well in Olympiads have freedom of thought. They can look at usual things in a new way, like great painters and poets do. Olympiads provide students with an opportunity to express and appreciate this creative freedom.

\section{Part II. A bridge between CMO problems and problems of mathematics: coloring a grid}

Mathematical research is a complex braid of ideas, calculations, constructions, etc. I would not offer at the Olympiad a problem that requires in its solution a lot of sweat, a lot of calculations. Why? Because at the review of solutions, a student may think 'no wonder I did not solve it'. I prefer to offer problems that allow brilliant concise solutions that prompt a student at the review to exclaim 'It is so easy, how did I not see it?' Yes, I favor solutions that are easy to see when I show them to my Olympians, but not easy to discover. I found a gold mine of original beautiful ideas in research mathematics. Like diamonds are mined from tons of soil, beautiful Olympiad-style ideas are extracted from massive research narratives. These diamonds in the rough are then dressed up - polished - to become attractive stories for younger people. This is a bridge from research to the Soifer Olympiad. On a number of occasions, an Olympiad problem becomes an inspiration for further exploration, for research. Enough talk! Let us look at a few related problems, at trains of thought, if you will.

I created the following problem in 2010 for the Colorado Mathematical Olympiad (CMO).

Won't you be my neighbor! (Soifer 2017, problem 5 of the 28th CMO in 2011, Soifer (2017)).

Each unit square of a $2011 \times 2011$ square grid is colored in one of 2011 colors so that each color is used. A pair of distinct colors is called a neighbor pair if they appear as colors of a pair of unit squares sharing a side.

(A). Find the maximum $M$ of the number of neighbor pairs.

(B). Find the minimum $m$ of the number of neighbor pairs.

Solution. Form a graph $G$ with 2011 vertices, one per color, and two vertices adjacent if and only if the corresponding colors form a neighbor pair somewhere on the colored grid. The graph $G$ is connected, for there is always a rook's path on the grid connecting unit squares of any

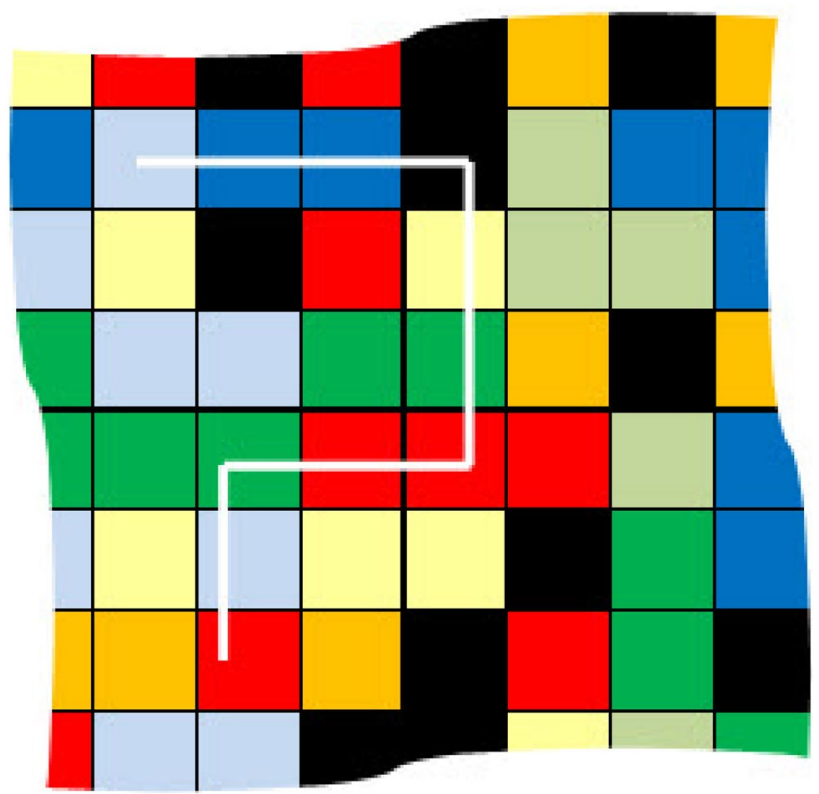

Fig. 1 Rook's path

Fig. 2 A tree

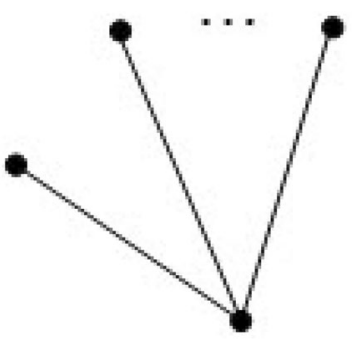

pair of colors (Fig. 1). Where the color along the path changes, we get an edge in $G$. Thus, every two vertices of $G$ are connected by a path along its edges, and hence, $G$ is connected.

Any tree on 2011 vertices features the minimum number 2010 of edges in a connected graph (an easy proof by mathematical induction); the complete graph $\mathrm{K}_{2011}$ (i.e., the graph where every pair of vertices is adjacent) sports the maximum number $\left(\begin{array}{c}2011 \\ 2\end{array}\right)$ of edges. All there is left to demonstrate is a coloring of the grid that induces a tree graph $T$, and a coloring of the grid that induces the complete graph $\mathrm{K}_{2011}$.

In order to achieve a tree, we first color the $2011 \times 2011$ square grid in a chessboard fashion in color 1 and a temporary color 2012. We then replace color 2012 with colors $2,3, \ldots, 2011$ with each of these colors used on at least one unit square. We get a tree with the root at the vertex corresponding to color 1 , and 2010 edges connecting this vertex to all other 2010 vertices of the graph (Fig. 2). 
Let us now induce the complete graph $\mathrm{K}_{2011}$.

Row 1 we color in two alternating colors, 1 and the temporary color 2012. We then replace the color 2012 with one unit square of each of the colors $2,3, \ldots, 1006$.

Row 2 we color in two alternating colors, 2 and the temporary color 2012. We then replace the color 2012 with one unit square of each of the colors $3,4, \ldots, 1007$; and so on.

Row 2011 we color in two alternating colors, 2011 and the temporary color 2012. We then replace the color 2012 with one unit square of each of the colors $1,2, \ldots, 1005$.

Due to the cyclical nature of the coloring, it suffices to verify that color 1 neighbors on each of the other colors. It neighbors on colors $2,3, \ldots, 1006$ in the first row. For $1007 \leq i \leq 2011$, color $i$ neighbors on color 1 in the row $i$, where color $i$ neighbors on colors $i+1, i+2, \ldots, i+1006$ (we calculate these sums modulo 2011, i.e., subtract 2011 from the color number as soon as it exceeds 2011). Since $i+1 \leq 2012$ and $2013 \leq i+1006$, color 1 will appear as a neighbor of color $i$ in the row $i$.

This problem must have entered my subconscious universe-without me realizing it. Shortly after its creation, I created a related problem:

Problem of Neighboring Colors (Soifer). Each unit square of an $n \times n$ square grid is colored in one of $m$ colors, so that every two colors somewhere on the grid are neighbors, i.e., share a side. Find the maximum of $m$.

I immediately came up with colorings for small $n$, suggesting a conjecture:

Neighboring Colors Conjecture (Soifer). $\max m=2 n-1$.

It was not hard to show that for any $n, \max m \leq 2 n-1$, but a proof of the conjecture in the general case eluded me. And so I shared the problem with the 1990 and 1991 Colorado Mathematical Olympiad winner Matthew Kahle, now a Professor of Mathematics at Ohio State University, who in turn shared it with his Ph.D. student Francisco MartinezFigueroa. The three of us achieved good progress, but still did not prove the conjecture completely. First, we found that in 2010 Keith Edwards had shown that max $m=2 n-1$ for all sufficiently large $n$, but it was not clear how large $n$ must be, and the proof was not constructive. We proved the following results constructively:

Small $\mathbf{n}$ Theorem (Kahle et al., 2020). For any $n \leq 8$, max $m=2 n-1$.

Lower Bounds Theorem. For any positive integer $n$, max $m \geq 2 n-9$. Moreover:

*) if $n \equiv 0$ or $1(\bmod 4)$, then $\max m \geq 2 n-6$;

$* *)$ if $n \equiv 2(\bmod 4)$, then $\max m \geq 2 n-7$.
As you can see, a beautiful Olympiad problem led me to create an even more exciting problem, which proved to be too hard for the Olympiad. However, it gave three generations of mathematicians an opportunity to enjoy joint work on this problem. It could give you the pleasure of advancing the proof (or disproof) of the conjecture further!

\section{Part III. A bridge between CMO problems and problems of mathematics: Chess $7 \times 7$}

New Olympiad problems occur to us in mysterious ways. This problem came to me one summer morning of 2003 as I was reading a never published 1980s manuscript of a Ramsey Theory monograph, while sitting by a mountain lake in the Bavarian Alps. It all started with my finding a hole in a lemma, which prompted a construction of a counterexample (part b of the present problem). Problem (a) is a corrected particular case of that lemma, translated, of course, into the language of a nice 'real' story of a chess tournament. I found three distinct striking solutions of (a) and an even more special solution of (b). As a result, this problem became my favorite Olympiad problem of the many problems I created over decades. What is more, the journey that lead me from Ramsey Theory to problems of mathematical Olympiads, continued to finite projective planes! In 2004 I presented these solutions at ICME-10 in Copenhagen.

Chess $7 \times 7$ (Soifer, problem 5 of the 21st Colorado Mathematical Olympiad, April 16, 2004).

(a) Each member of two 7-member chess teams is to play once against each member of the opposing team. Prove that as soon as 22 games have been played, we can choose 4 players and seat them at a round table so that each pair of neighbors has already played.

(b) Prove that 22 is the best possible minimum choice; i.e., after 21 games the result of (a) cannot be guaranteed.

(a) Solution 1. This solution exploits an algebraic description of convexity. Given an array of real numbers $x_{1}, x_{2}, \ldots, x_{7}$ of arithmetic mean $\bar{x}$. A well known inequality (that can be derived from the arithmetic-geometric mean inequality) states that

$\sqrt{\frac{\sum_{i=1}^{7} x_{i}^{2}}{7}} \geq \bar{x}$

Thus 
$\sum_{i=1}^{7} x_{i}^{2} \geq 7 \bar{x}^{2}$

This inequality defines the 'convexity' of the function $f(x)=x^{2}$, which easily implies the convexity of a binomial function $\left(\begin{array}{l}x \\ 2\end{array}\right)=\frac{1}{2} x(x-1)$,

i.e.,

$$
\sum_{i=1}^{7}\left(\begin{array}{l}
x_{i} \\
2
\end{array}\right) \geq 7\left(\begin{array}{l}
\bar{x} \\
2
\end{array}\right)
$$

Observe that above we defined the binomial function $\left(\begin{array}{l}x \\ 2\end{array}\right)$ for all real $x$ (not just for positive integers). Also, in a certain informality of notations, for integral $x$ we would use $\left(\begin{array}{l}x \\ 2\end{array}\right)$ not only as a number, but also as a set of all 2-element subsets of the set $\{1,2, \ldots, x\}$.

Let us call the players inside each team by positive integers $1,2, \ldots, 7$. A game between player $i$ of the first team with a player $j$ of the second team can conveniently be denoted by an ordered pair $(i, j)$. Assume that the set $G$ of 22 games has been played.

Denote by $S(j)$ the number of games played by the player $j$ of the second team: $S(j)=|\{i:(i, j) \in G\}|$. Obviously, $\sum_{j=1}^{7} S(j)=22$.

For a pair $\left(i_{1}, i_{2}\right)$ of the first team players denote by $C\left(i_{1}, i_{2}\right)$ the number of second team players $j$, who played with both of this pair's first team players: $C\left(i_{1}, i_{2}\right)=\left|\left\{j:\left(i_{1}, j\right) \in G \wedge\left(i_{2}, j\right) \in G\right\}\right|$. Adding all $C\left(i_{1}, i_{2}\right)$ together $T=\sum_{\left(i_{1}, i_{2}\right) \in\left(\begin{array}{l}7 \\ 2\end{array}\right)} C\left(i_{1}, i_{2}\right)$ counts the number of triples $\left(i_{1}, i_{2} ; j\right)$ such that each of the first team's players $i_{1}, i_{2}$ has played with the same player $j$ of the second team. This number $T$ can be alternatively calculated as follows: $T=\sum_{\mathrm{j}=1}^{7}\left(\begin{array}{c}S(j) \\ 2\end{array}\right)$. Therefore, we get the equality $\sum_{\left(i_{1}, i_{2}\right) \in\left(\begin{array}{l}7 \\ 2\end{array}\right)} C\left(i_{1}, i_{2}\right)=\sum_{\mathrm{j}=1}^{7}\left(\begin{array}{c}S(j) \\ 2\end{array}\right)$. In view of the convexity inequality $(0.1)$, we finally get

$$
\begin{aligned}
\sum_{\left(i_{1}, i_{2}\right) \in\left(\begin{array}{l}
7 \\
2
\end{array}\right)} C\left(i_{1}, i_{2}\right) & =\sum_{j=1}^{7}\left(\begin{array}{c}
S(j) \\
2
\end{array}\right) \geq 7\left(\begin{array}{l}
\frac{\sum_{j=1}^{7} S(j)}{7} \\
2
\end{array}\right) \\
& =7\left(\begin{array}{l}
\frac{22}{7} \\
2
\end{array}\right)>7\left(\begin{array}{l}
3 \\
2
\end{array}\right)=\left(\begin{array}{l}
7 \\
2
\end{array}\right)
\end{aligned}
$$

i.e.,

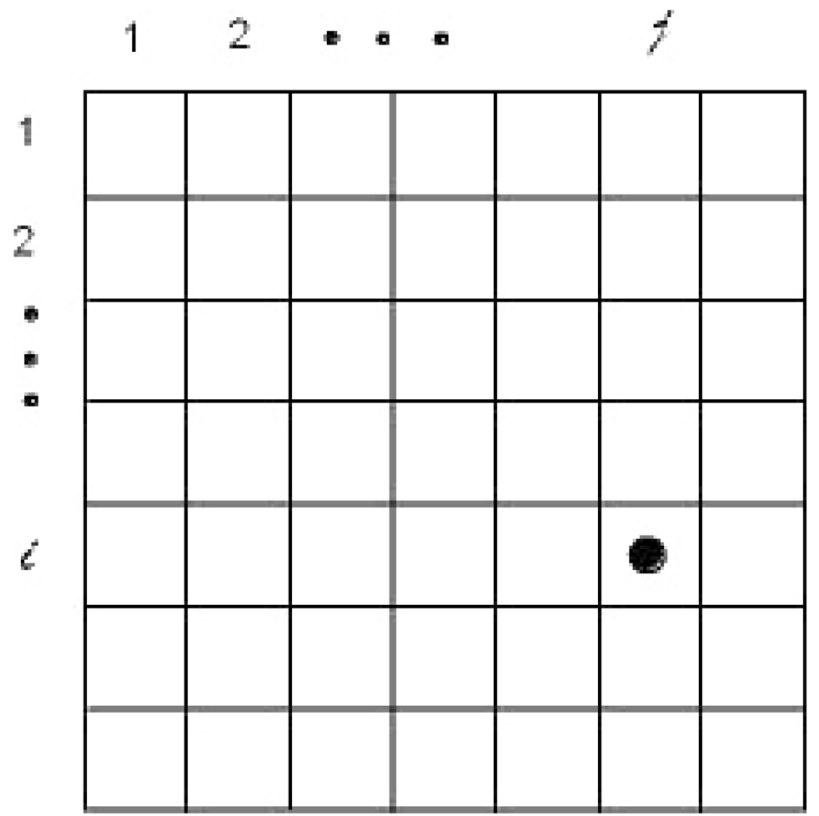

Fig. 3 A checker representing a game played

$$
\sum_{\left(i_{1}, i_{2}\right) \in\left(\begin{array}{l}
7 \\
2
\end{array}\right)} C\left(i_{1}, i_{2}\right)>\left(\begin{array}{l}
7 \\
2
\end{array}\right)
$$

We got the sum of $\left(\begin{array}{l}7 \\ 2\end{array}\right)$ non-negative integers to be greater than $\left(\begin{array}{l}7 \\ 2\end{array}\right)$, therefore, at least one of the summands, $C\left(i_{1}, i_{2}\right) \geq 2$. In our notation this means precisely that the pair of first team players $i_{1}, i_{2}$ played with the same two (or more) players $j_{1}, j_{2}$ of the second team. Surely, you can seat these four players at a round table in accordance with the problem's requirements!

(a) Solution 2. This solution harnesses the power of combinatorics.

In the selection and editing process, Dr. Col. Bob Ewell, a senior judge of the Olympiad, suggested using a $7 \times 7$ table to record the games played. We number the players in both teams. For each player of the first team we allocate a row of the table, and for each player of the second team a column. We place a checker in the table in location $(i, j)$ if the player $i$ of the first team played the player $j$ of the second team (Fig. 3).

If the required four players are found, this would manifest itself in the table as a rectangle formed by four checkers (a checkered rectangle)! The problem thus translates into the new language as follows: 


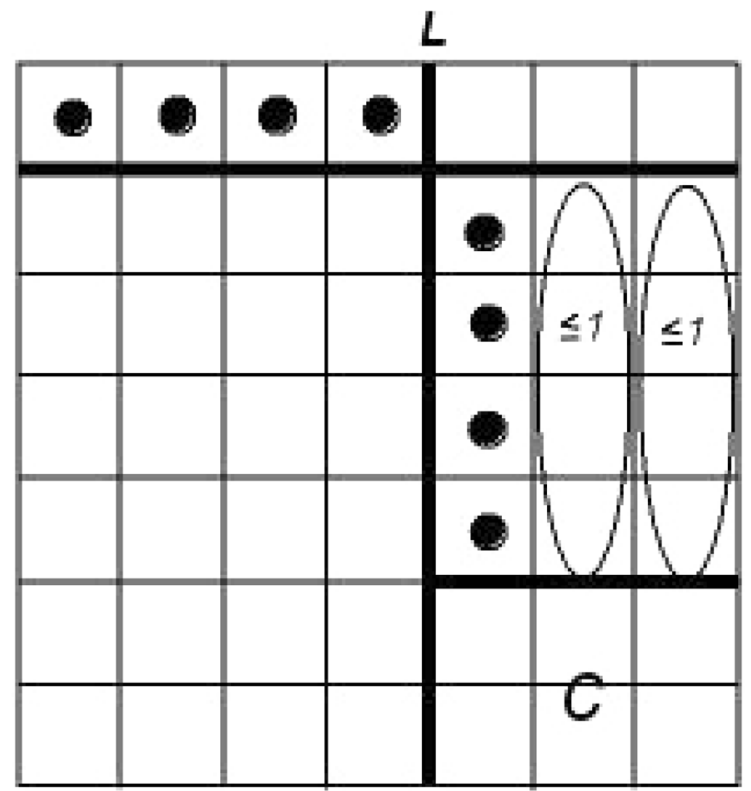

Fig. 4 A case of 4 checkers in a row

A $7 \times 7$ table with 22 checkers must contain a checkered rectangle.

Assume that a table has 22 checkers but does not contain a checkered rectangle. Since 22 checkers are contained in 7 rows, by the Pigeonhole Principle, there is a row with at least 4 checkers in it. Observe that interchanging rows or columns does not affect the property of the table of having or not having a checkered rectangle. By interchanging rows we make the row with at least 4 checkers first. By interchanging columns we make all checkers appear consecutively from the left of the first column. We consider two cases.

(1) The top column contains exactly 4 checkers (Fig. 4).

Draw a bold vertical line $L$ after the first 4 columns. To the left from $L$, the top row contains 4 checkers, and all other rows contain at most 1 checker each, for otherwise we would have a checkered rectangle (that includes the top row). Therefore, to the left from $L$ we have at most $4+6=10$ checkers. This leaves at least 12 checkers to the right of $L$, thus at least one of the three columns to the right of $L$ contains at least 4 checkers; by interchanging columns and rows we put them in the position shown in Fig. 4. Then each of the two right columns contains at most 1 checker total in the rows 2 through 5 , for otherwise we would have a checkered rectangle. We thus have at most $4+1+1=6$ checkers to the right of $L$ in rows 2 through 5 combined. Therefore, in the lower right $2 \times 3$ part $C$ of the table we have at least $22-10$ $-6=6$ checkers - thus $C$ is completely filled with checkers, and we get a checkered rectangle in $C$ in contradiction to our assumption.

(2) The top column contains at least 5 checkers (Fig. 5).

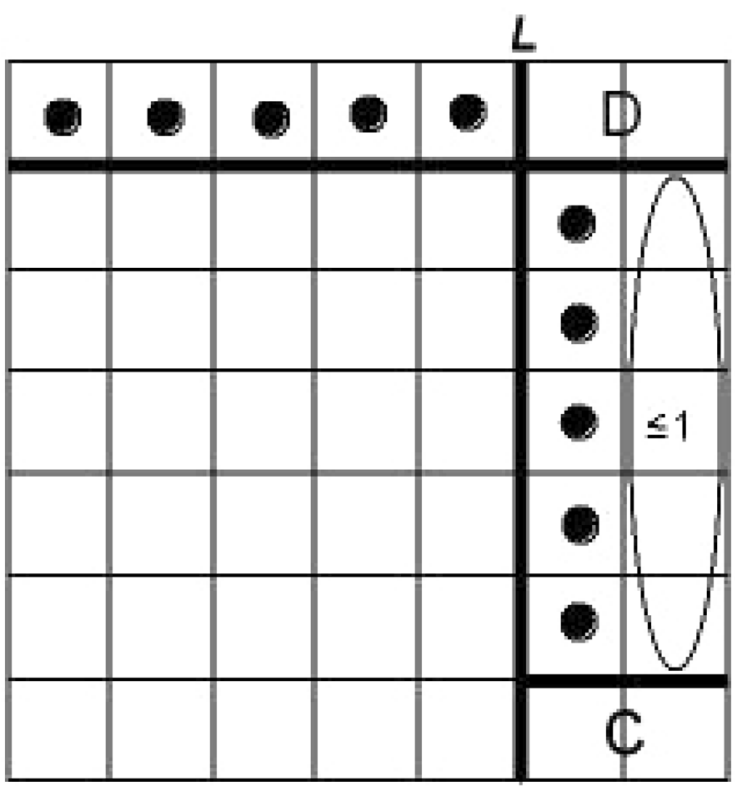

Fig. 5 A case of at least 5 checkers in a row

Draw a bold vertical line $L$ after the first 5 columns. To the left from $L$, the top row contains 5 checkers, and all other rows contain at most 1 checker each, for otherwise we would have a checkered rectangle (that includes the top row). Therefore, to the left from $L$ we have at most $5+6=11$ checkers. This leaves at least 11 checkers to the right of $L$, thus at least one of the two columns to the right of $L$ contains at least 6 checkers; by interchanging columns and rows we put 5 of these 6 checkers in the position shown in Fig. 5 . Then the last column contains at most 1 checker total in the rows 2 through 6 , for otherwise we would have a checkered rectangle. We thus have at most $5+1=6$ checkers to the right of $L$ in rows 2 through 6 combined. Therefore, the upper right $1 \times 2$ part $C$ of the table plus the lower right 1 $\times 2$ part $D$ of the table have together at least $22-11-6=5$ checkers-but they only have 4 cells, and we thus get a contradiction.

(a) Solution 3. This solution is the shortest of the three. It also 'explains' the meaning of the number 22 in the problem:

$$
22=\left(\begin{array}{l}
7 \\
2
\end{array}\right)+1
$$

Given a placement $P$ of 22 checkers on the $7 \times 7$ board, we pick one row; let this row have $k$ checkers total on it. We compute the number of 2-element subsets of a $k$-element set; this number is denoted by $\left(\begin{array}{l}k \\ 2\end{array}\right)$ and is equal to $\left(\begin{array}{l}k \\ 2\end{array}\right)=\frac{1}{2} k(k-1)$. Now we can define a function $C(P)$ as the 


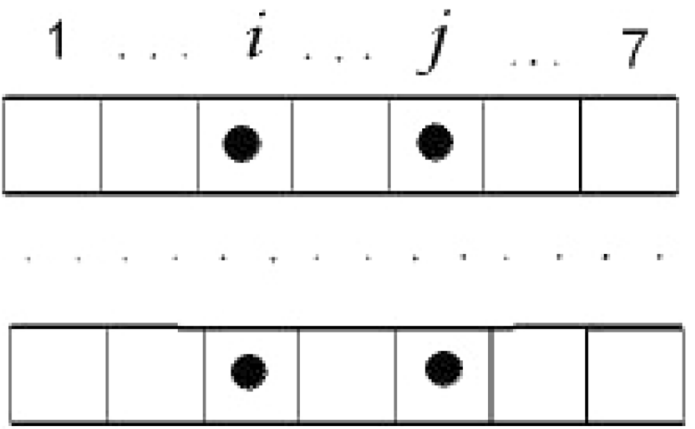

Fig. 6 A checkered rectangle

sum of 7 such summands $\left(\begin{array}{l}k \\ 2\end{array}\right)$, one per each row. Given a placement $P$ of 22 checkers on a $7 \times 7$ board. If there is a row $R$ with $r$ checkers, where $\mathrm{r}=0,1$, or 2 , then there is a row $S$ with $s$ checkers, where $\mathrm{s}=4,5,6$ or 7 (for the average number of checkers in a row is $22 / 7$ ). We notice that $s-r-1 \geq$ 0 , and observe that moving one checker from row $S$ to any open cell of row $R$ would produce a placement $P_{1}$ with reduced $C(P)>C\left(P_{1}\right)$ because

$\left(\begin{array}{l}r \\ 2\end{array}\right)+\left(\begin{array}{l}s \\ 2\end{array}\right)-\left(\begin{array}{l}r+1 \\ 2\end{array}\right)-\left(\begin{array}{l}s-1 \\ 2\end{array}\right)=s-r-1 \geq 0$

By moving one checker at a time, we will end up with the final placement $P_{k}$, where each row has 3 checkers except one, which has 4 . For the final placement $C\left(P_{k}\right)$ can be easily computed as $6\left(\begin{array}{l}3 \\ 2\end{array}\right)+\left(\begin{array}{l}4 \\ 2\end{array}\right)=24$. Thus, for the original placement $P, C(P)$ is at least 24 .

On the other hand, the total number of 2-element subsets in a 7-element set is $\left(\begin{array}{l}7 \\ 2\end{array}\right)=21$. Since $24>21$, there are two identical 2-element subsets (Fig. 6) among the 24 counted by the function $C(P)$. But the checkers that form these two identical pairs form a desired checkered rectangle!

Solution of (b). Glue a cylinder (!) out of the $7 \times 7$ board and put 21 checkers on all squares of the 1 st, 2 nd, and 4 th diagonals (Fig. 7 shows the cylinder with one checkered diagonal; Fig. 8 shows, in a flat representation, the cylinder with all three cylinder diagonals).

Assume that 4 checkers form a rectangle on our $7 \times 7$ board. Since these four checkers lie on 3 diagonals, by the Pigeonhole Principle two checkers lie on the same (checker-covered) diagonal $D$ of the cylinder. But this means that on the cylinder our 4 checkers form a square! Two other (opposite) checkers $a$ and $b$ thus must be symmetric to each other with respect to $D$, which implies that
Fig. 7 A cylinder with one checkered diagonal shown
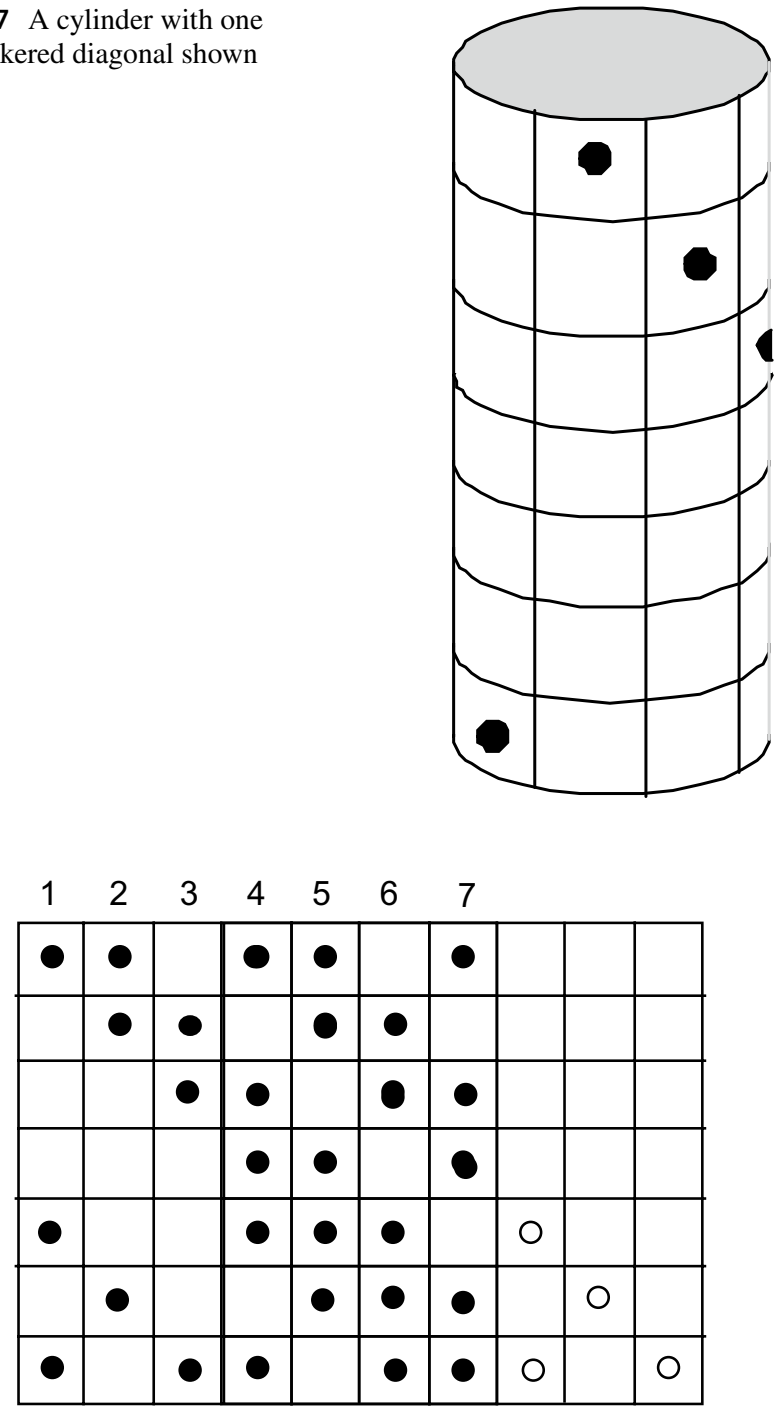

Fig. 8 A plane representation of diagonally placed 22 rooks

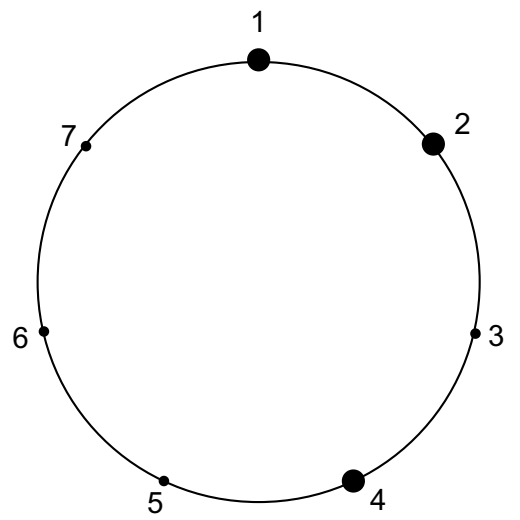

Fig. 9 View from above on three checkered diagonals 


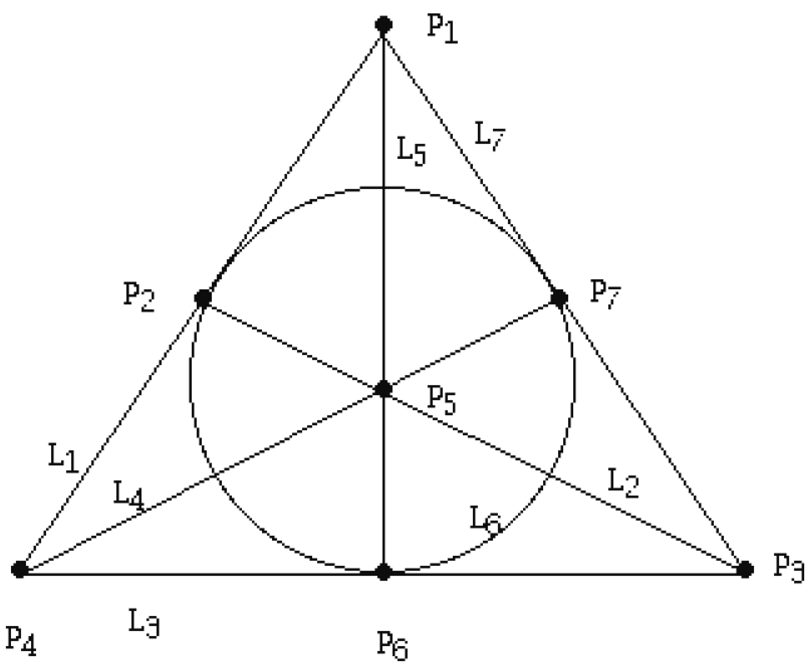

Fig. 10 The fano plane $P G(2,2)$

the diagonals of the cylinder that contain $a$ and $b$ must be symmetric with respect to $D$-but no 2 checker-covered diagonals in our checker placement are symmetric with respect to $D$. To see this, observe Fig. 9 which shows the top rim of the cylinder with bold dots for checkered diagonals: square distances between the checkered diagonals, clockwise, are 1,2, and 4 . This contradiction implies that there are no checkered rectangles in our placement. Done!

Remark on Problem (b). Obviously, any solution of problem (b) can be presented in a form of 21 checkers on a $7 \times$ 7 board (left $7 \times 7$ part with 21 black checkers in Fig. 8 ). It is less obvious, that the solution is unique: by a series of interchanges of rows and columns, any solution of this problem can be brought to precisely the one presented! Of course, such interchanges mean merely renumbering of players of the same team. The uniqueness of the solution of problem (b) is precisely another way of stating the uniqueness of the projective plane ${ }^{1}$ of order 2 , the so called 'Fano Plane'2 denoted by $P G(2,2)$. The Fano Plane is an abstract construction, with symmetry between points and lines: it has 7 points and 7 lines (think of rows and columns of our $7 \times 7$ board as lines and points respectively!), with 3 points on every line and 3 lines through every point (Fig. 10).

\footnotetext{
1 A finite projective plane of order $n$ is defined as a set of $n^{2}+n+1$ points with the properties that:

1. Any two points determine a line,

2. Any two lines determine a point

3. Every point has $n+1$ lines through it,

4. Every line contains $n+1$ points.

2 Named after Gino Fano (1871-1952), the Italian geometer who pioneered the study of finite geometries.
}

Observe that if in our $7 \times 7$ board (left side in Fig. 8) we replace checkers by 1 and the rest of the squares by zeroes, we would get the incidence matrix of the Fano Plane.

\section{Part IV. A bridge between CMO problems and problems of mathematics: love and death}

For the 22nd Colorado Math Olympiad, I decided to create a problem about genetics. I consulted with a biology professor to make my numbers realistic. This idea proved fruitful: our Olympians enjoyed a 'real life' problem.

Love and Death (Soifer, problem 5 of the 22st Colorado Mathematical Olympiad, April 22, 2005).

(A) The DNA of the bacterium bacillus anthracis (causing anthrax) is a sequence, each term of which is one of 2005 genes. How long can the DNA be if no two consecutive terms may be the same gene, and no two distinct genes can reappear in the same order? That is, if distinct genes $\alpha, \beta$ occur in that order (with or without any number of genes in between), the order $\alpha, \ldots, \beta$ cannot occur again.

(B) The DNA of the bacterium bacillus amoris (causing love) is a sequence, each term of which is one of 2005 genes. No three consecutive terms may include the same gene more than once, and no three distinct genes can reappear in the same order. That is, if distinct genes $\alpha, \beta$, and $\gamma$ occur in that order (with or without any number of genes in between), the order $\alpha, \ldots, \beta, \ldots, \gamma$ cannot occur again. Prove that this DNA is at most 12,032 long.

22.5. (A). First Solution. Let us prove that in DNA satisfying the two given conditions, there is a gene that occurs only once. Indeed, let us assume that each gene appears at least twice and for each gene select the first two appearances from the left and call them a pair. The first gene from the left is in the first pair. This pair must be separated, thus the pair of the second gene from the left is nestled inside the first pair. The second pair must be separated, and thus the pair of the third gene from the left must be nestled inside the second pair, etc. As there are finitely many genes, we end up with a pair of genes (nestled inside other pairs) that is not separated, a contradiction.

We now prove by mathematical induction on the number $n$ of genes, that the DNA that satisfies the conditions and uses $n$ genes is at most $2 n-1$ genes long. For $n=1$ the statement is true, as the longest DNA is $2-1=1$ gene long.

Assume that DNA that satisfies the required conditions and uses $n$ genes is at most $2 n-1$ genes long. Now let $S$ be a DNA sequence satisfying the conditions that uses $n+1$ genes; we need to prove that it is at most $2(n+1)-1=2 n+1$ genes long. 
Fig. 11 Case 1 of genes configuration
A

\begin{tabular}{|l|l|l|}
\hline$\alpha$ & $\beta$ & $\gamma$ \\
\hline
\end{tabular}

In the first paragraph of our solution, we proved that there is a gene $g$ that occurs only once in $S$; we throw it away. The only violation that this throwing may create is that two copies of another gene become adjacent-if so, we throw one of them away too. We get the sequence $S$ ' that uses only $n$ genes. By the inductive assumption, $S^{\prime}$ is at most $2 n-1$ genes long. But $S$ is at most 2 genes longer than $S$, i.e., $S$ is at most $2 n+1$ genes long. The induction is complete.

All that is left is to demonstrate that the DNA length of $2 n-1$ is attainable. But this is easy: just pick the following sequence $1,2, \ldots, n-1, n, n-1, \ldots, 2,1$.

22.5. (A). Second Solution. We prove by mathematical induction on the number $n$ of genes, that the DNA that satisfies the problem conditions and uses $n$ genes is at most $2 n$ -1 genes long. For $n=1$ the statement is true, as the longest DNA is $2-1=1$ gene long.

Assume that for any positive integer $k, k<n$, DNA that satisfies the conditions and uses $k$ genes, is at most $2 k-1$ genes long. Now let $S$ be the longest DNA sequence that satisfies the problem conditions and uses $n$ genes; we need to prove that $S$ is at most $2 n-1$ genes long.

Let the first gene of $S$ be 1, then the last term must be 1 as well, for otherwise we can make $S$ longer by adding a 1 at the end. Indeed, assume that the added 1 has created a forbidden DNA. This means that we now have a subsequence $a, \ldots, 1, \ldots, a, \ldots, 1$ (with the added 1 at the end); but then the original DNA, that started with 1 , already had the forbidden subsequence $1, \ldots, a, \ldots, 1, \ldots, a$.

Let us consider two cases.

Case 1. If there are no more $1 \mathrm{~s}$ in the DNA, we throw away the first 1 and the last 1 , and we get a sequence $S$ ' that uses $n-1$ genes (no more 1 's). By the inductive assumption, $S$ ' is at most $2 n-1$ genes long. But $S$ is 2 genes longer than $S$, i.e., $S$ is at most $2 n+1$ genes long.

Case 2. Assume now that there is a 1 between the first 1 and the last 1. The DNA then looks as follows: 1, $S, 1, S^{\prime}, 1$. Observe that if a gene $m$ appears in the sequence $S$, it may not appear in the sequence $S^{\prime}$, for this would create the prohibited subsequence $1, \ldots, m, \ldots, 1, \ldots, m$. Let the sequence $1, S, 1$ use
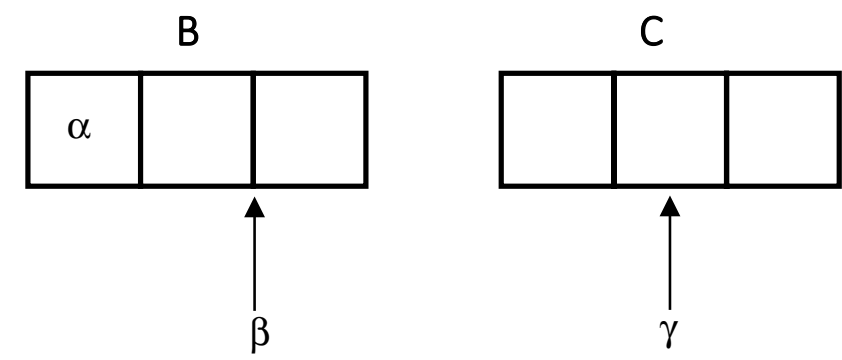

$n$ ' genes and the sequence $1, S^{\prime \prime}, 1$ use $n$ " genes. Obviously, $n^{\prime}+n^{\prime \prime}-1=n$ (we subtract 1 in the left side because we counted the gene 1 in each of the two subsequences). By the inductive assumption, the lengths of the sequences $1, S, 1$ and 1 , $S ", 1$ are at most $2 n '-1$ and $2 n "-1$ respectively. Therefore, the length of $S$ is $\left(2 n^{\prime}-1\right)+\left(2 n^{\prime \prime}-1\right)-$ 1 (we subtract 1 because the gene 1 between $S$ ' and $S^{\prime}$ has been counted twice). But $\left(2 n^{\prime}-1\right)+\left(2 n^{\prime \prime}\right.$ $-1)-1=2\left(n^{\prime}+n^{\prime \prime}\right)-3=2(n+1)-3=2 n-1$ as desired. The induction is complete.

This proof allows us to find a richer set of examples of DNA of length of $2 n-1$ (and even describe all such examples if necessary). For example:

$$
1,2, \ldots, k, k+1, k, k+2, \boldsymbol{k}, \ldots, \boldsymbol{k}, 2005, \boldsymbol{k}, \boldsymbol{k}-1, k-2,
$$
$\ldots, 2,1$.

22.5.(B). Assume $S$ is the longest DNA string satisfying the problem conditions. Partition $S$ into blocks of 3 terms starting from the left (the last block may be incomplete and have fewer than 3 terms, of course). We call a block extreme if a number from the given set of genes $\{1,2, \ldots, 2005\}$ appears in the block for the first or the last time. There are at most $2 \times 2005$ extreme blocks.

We claim that there are no complete (i.e., 3-gene) nonextreme blocks.

Indeed, assume the block $\mathbf{B}$, which consists of genes $\alpha, \beta$ ,$\gamma$ in some order, is not extreme (in the original DNA string $S$ these three genes do not have to be consecutive). This means that the genes $\alpha, \beta, \gamma$ each appear at least once before and at least once after appearing in $\mathbf{B}$. We prove that then the DNA would contain the forbidden subsequence of the type $\sigma, \tau, \omega, \sigma, \tau, \omega$. Let $\mathbf{A}$ denote the ordered triple of the first appearances of $\alpha, \beta, \gamma$ (these 3 genes may very well come from distinct 3-blocks). Without loss of generality we can assume that in $A$ the genes $\alpha, \beta, \gamma$ appear in this order. Let $\mathbf{C}$ denote the ordered triple of the last appearances of $\alpha, \beta, \gamma$ in some order. Let us look at the 9-term subsequence ABC and consider three cases, depending upon where $\alpha$ appears in the block $\mathbf{B}$. 
Fig. 12 Case 2 of genes configuration

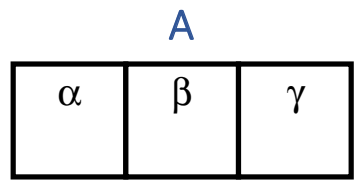

Fig. 13 Case 3 of genes configuration

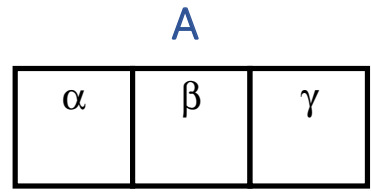

Case 1. If $\alpha$ is the first gene in $\mathbf{B}$ (Fig. 11), then we can choose $\beta$ also in $\mathbf{B}$ and $\gamma$ in $\mathbf{C}$ to form $\alpha, \beta, \gamma$ which with $\alpha, \beta, \gamma$ from $\mathbf{A}$ gives us the forbidden sequence $\alpha, \beta, \gamma \alpha, \beta, \gamma$.

Case 2. Let $\alpha$ be the second gene in $\mathbf{B}$ (Fig. 12). If $\beta$ follows $\alpha$, then with $\gamma$ from $\mathbf{C}$ we get $\alpha, \beta, \gamma$ which with $\alpha, \beta, \gamma$ from $\mathbf{A}$ produces the forbidden sequence $\alpha, \beta$ $, \gamma \alpha, \beta, \gamma$. Thus, $\beta$ must precede $\alpha$ in $\mathbf{B}$. If the order of the genes $\beta, \gamma$ in $\mathbf{C}$ is $\beta, \gamma$, then we can combine an $\alpha$ from $\mathbf{B}$ with this $\beta, \gamma$ to form $\alpha, \beta, \gamma$, which with $\alpha, \beta, \gamma$ from $\mathbf{A}$ gives us the forbidden $\alpha, \beta, \gamma \alpha$ $, \beta, \gamma$. Thus, the order in $\mathbf{C}$ must be $\gamma, \beta$. Now we can choose $\alpha, \gamma$ from $\mathbf{A}$ followed by $\beta, \alpha$ from $\mathbf{B}$, followed by $\gamma, \beta$ from $\mathbf{C}$ to get $\alpha, \gamma, \beta \alpha, \gamma, \beta$, which is forbidden.

Case 3. Let $\alpha$ be the third gene in $\mathbf{B}$ (Fig. 13), which is thus preceded by $\beta$ in $\mathbf{B}$. If the order in $\mathbf{C}$ is $\beta, \gamma$ then we get $\alpha, \beta, \gamma$ from $\mathbf{A}$ followed by $\alpha$ from $\mathbf{B}$ and $\beta, \gamma$ from $\mathbf{C}$ to get the forbidden $\alpha, \beta, \gamma \alpha, \beta, \gamma$. Thus, the order in $\mathbf{C}$ must be $\gamma, \beta$, and we choose $\alpha, \gamma$ from $\mathbf{A}$, followed by $\beta, \alpha$ from $\mathbf{B}$, and followed by $\gamma, \beta$ from $\mathbf{C}$ to form the forbidden $\alpha, \gamma, \beta, \alpha, \gamma, \beta$.

We are done, for the DNA sequence consists of at most $2 \times 2005$ extreme 3 -blocks plus perhaps an incomplete block of at most 2 genes-or 12,032 genes at the most.

In my 2017 Olympiad book, I continued this train of thought in Further Exploration E23 (Soifer, 2017). In it, I presented a stronger bound, obtained by Professor Martin Klazar of Prague.
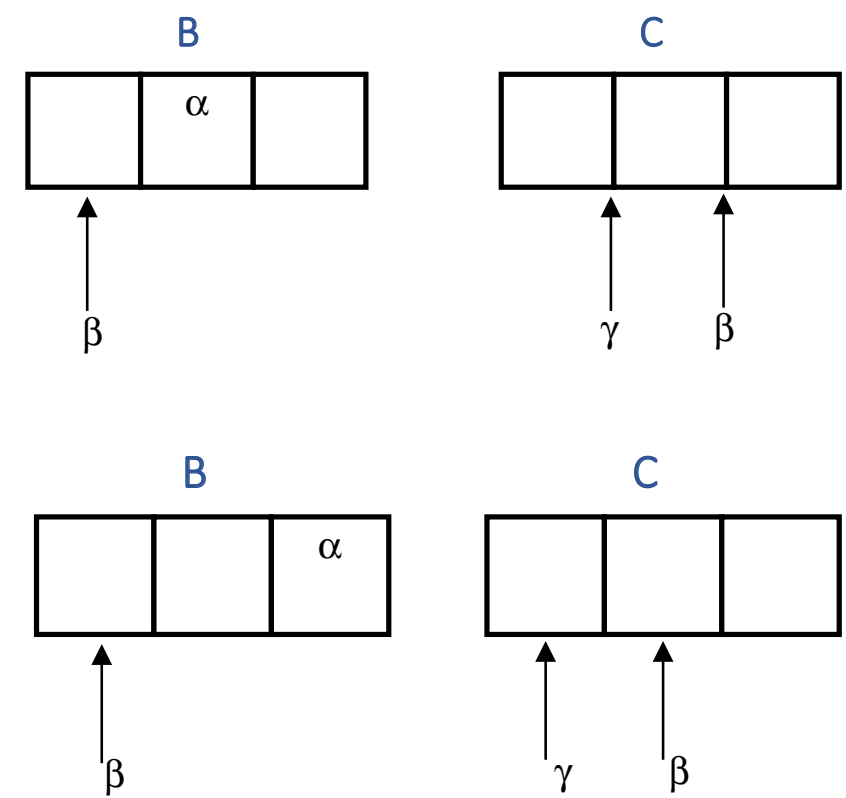

\section{Exploration E23: more about Love and Death}

\subsection{Inspired by the problem 'Love and Death'}

I hope you did not take the DNAs featured in my problem 22.5 to faithfully reflect reality. Remember, we are in the Illusory World of Mathematics! To whet your appetite for the problem, I invented the bacterium bacillus anthracis, causing anthrax (death), in problem 22.5.(A). In problem 22.5.(B), I went even further by imagining the bacterium bacillus amoris, causing love.:). I was inspired by a talk by a Ph.D. student Martin Klazar that I attended during my long term visit to Charles University in the beautiful Prague, Czech Republic. Now Martin is a professor at that same university. The notes I took in 1996 during Klazar's talk, contained at the end the following remark:

By overlapping the 3-gene blocks by their end terms and using the same argument, Martin showed that the upper bound can be reduced from $6 n+2$ ( $n$ is here the number of available genes) to $4 n+2$, and with clever observation of the starting and ending triples to even $4 n-4$. It is possible to achieve the bound of $4 n-7$, proof of which would require further cleverness.

These bounds, of course, are stronger than the ones I asked for in problem 22.5 (B). Their proofs were not presented during Klazar's talk. Now, Twenty Years After, as Alexandre Dumas named his sequel to The Three Musketeers, I asked Martin Klazar to enlighten us. Here is his 
reply of September 12, 2016, containing the proof of a much stronger upper bound, with my minimal stylistic editing.

Dear Sasha,

Here is my proof that a 3-sparse word $u$ [i.e., no three consecutive terms in $u$ may include the same gene more than once] over an $n$-element alphabet avoiding the pattern $a b c a b c$ as a subsequence has length at most $4 n-4$ (for $n>1$ ).

We denote by $F$ the first occurrences (of a letter) in $u$, by $L$ the last occurrences, and by $S$ the intersection $F \cap L$. The intersection consists of exactly the letters that appear in $u$ just once.

We may assume that $u$ has the length $|u|$ of at least six (else the bound holds) and split $u$ into three words $u=$ $u^{\prime} v u^{\prime \prime}$ where $\left|u^{\prime}\right|=\left|u^{\prime}\right|=3$. Note that each of the three terms of $u$ ' lies in $F$ and those of $u$ " lie in $L$.

We look now for an upper bound of the length $|v|$ of the middle part of $u$. We cover $v$ by $k$ intervals $I_{1}, \ldots, I_{k}$ of length 3 each and by at most one residual term at the end, so that $I_{i}$ and $I_{i+1}$ share their endpoints (thus if $v$ $=$ abcadec $a$ then $I_{1}=a b c, I_{2}=c a d, I_{3}=d e c$ plus the residual term $a$ ). If $k=0$ then there may be two residual terms. Hence $|v|$ is at most $3+2(k-1)+1=2 k+2$. Consider one of these intervals $I=I_{i}=x y z$. By the sparseness condition for $u$, the $x, y, z$ are of course distinct. If $x$ is not in $L, y$ is not in $F \cup L$, and $z$ is not in $F$, then $u$ has an $a b c a b c$ subsequence (for then $y$, $z$ are forced to appear before $I$ and $x, y$ after $I$ ). Thus at least one of the following statements is true: ( $x$ is in $L)$ or $(y$ is in $F \cup L)$ or $(z$ is in $F)$. I select one of these three elements of $I$ (i.e., one for which the clause holds) and call it good (so all three terms in I may be good, or two of them, but certainly at least one term of $I$ is good). I hope now it is clear what I meant then by 'good' elements.

Let $G$ be the set of good terms in $v$.

We bound $k$ by the number $|G|$ of good terms in $v$. Since $G$ is a subset of $F \cup L$, we have that $|G|$ is at most $2 n$. Since the $I_{i}$ are not disjoint, we may have chosen some $g$ in $G$ for two (but not more) intervals $I_{i}$. But if this happens then $g$ is the last term in $I_{i}$, the first term in $I_{i+1}$, and is in $S$. Thus, $k$ is at mostl $F \cup L$ l' where the apostrophe means that each element of the subset $S$ of $F \cup L$ is counted with weight 2 . But we still have that $|F \cup L|$ ' is at most $2 n$ (it is $<2 n$ only if some of the $n$ letters do not appear in $u$ at all), and so $k$ is at most $2 n$. But $k$ is in fact at most $2 n-6$ because the 6 terms in $u$ ' and $u$ " lie in $F \cup L$ and not in $S$, but not in $v$ and are not used in any $I_{i}$.

Summarizing, $|u|=\left|u^{\prime}\right|+|v|+\left|u^{\prime}\right|=6+|v|$, which is at most $6+2 k+2$, which is at most $6+2(2 n-6)+$ $2=4 n-4$.
Best,

Martin

P.S.: I do not know [a] better bound. I think I have somewhere stated and proved some lower bound and posed a problem to determine the extremal function $\operatorname{Ex}(a b c a b c, n)$ exactly, which should be doable, but as far as I know, has not been done.

Let us formulate the results we in fact proved in the 'Love and Death' problem in the notations of Martin Klazar's post scriptum.

Love and Death (A). $\operatorname{Ex}(a b a b, n)=2 n-1$.

Love and Death (B). $E x(a b c a b c, n) \leq 6 n+2$.

In this notation, Martin proved above the following result:

Upper Bound (Martin Klazar). Ex(abcabc, $n) \leq 4 n-4$.

You have an opportunity to improve Martin's result while working on his open problem:

Open Problem (Martin Klazar). Find the exact value for $\operatorname{Ex}(a b c a b c, n)$.

Did you get hooked on these sequences and would like to learn and solve more? Let me quote a paragraph from a relevant page of Wikipedia, so that you will know what to search for:

In combinatorics, a Davenport-Schinzel sequence is a sequence of symbols in which the number of times any two symbols may appear in alternation is limited. The maximum possible length of a Davenport-Schinzel sequence is bounded by the number of its distinct symbols multiplied by a small but non-constant factor that depends on the number of alternations that are allowed. Davenport-Schinzel sequences were first defined in 1965 by Harold Davenport and Andrzej Schinzel.

Then there came to me a most surprising invitation from Singapore scholars:

It is our great pleasure and privilege to welcome you to join the Annual World Congress of Food and Nutrition, which will be held in Singapore. On behalf of the Organizing Committee, we would be honored to invite you to be a chair/speaker at Session 405: Foodborne Diseases, Carcinogenic Food while presenting about E23: More about Love and Death at the upcoming WCFN.

The organizers of the World Congress somehow dug out the title of my 'Further Exploration' from The Colorado Mathematical Olympiad books (Soifer, 2011, 2017) and interpreted the Olympiad problem title literally! 


\section{Part V. Case study in 3 movements: Olympiad winners reminisce}

In my two Springer books on the Colorado Mathematical Olympiad (Soifer, 2011, 2017), I included something I have not seen in other Olympiad books: I asked winners to write their reminiscences about the Olympiad, its role in their lives, and where that life took them. The reproduced below invaluable feedback first appeared in the 2017 book. As you will discover reading these memoirs, our winners are perceptive and talented writers.

\subsection{Movement 1." The Colorado Mathematical Olympiad is mathematics; it is sport; it is art. And it is also community" by Matthew Kahle, Professor of Mathematics, Ohio State University}

Professor Soifer asked me to share some reminiscences for his new book. I am happy to! First, I will reprint parts of an essay I wrote in 2008, for an earlier Olympiad book.

Professor Alexander 'Sasha' Soifer told me that for the new edition of the Colorado Mathematical Olympiad book, he wanted to include a chapter written by past winners, about the role of the Olympiad in their lives, their view of math, and their future careers. I am very happy to contribute an essay for this.

I want to emphasize that there are many features of the CMO [the Colorado Mathematical Olympiad] that distinguish it in my mind from the other contests which I competed in. First, the format itself was different from most competitions-five questions and four hours! It is true that there are other Olympiad style contests that I would come across years later (USAMO, Putnam, ...), but I first sat for the CMO as an 8th grader, when our teacher and coach Betty Daniels took a few of us from the middle school to UCCS [University of Colorado at Colorado Springs] for the Olympiad.

None of us had ever seen an exam like this before! I remember Sasha coming around to the rooms at the beginning of the day, asking if anyone had questions. I think I asked him if we could use calculators. He smiled impishly, shrugged his shoulders and said, 'Sure, why not?' (Perhaps, needless to say, calculators weren't much help.) I am pretty sure that I spent the whole four hours every year I took it, even in eighth grade, and I never solved all of the problems. But it was not an ordeal for me to take a four-hour math test; I could leave any time I wanted. I stayed until the end because I was having fun. This might be one of the most important qualities that separate the CMO in my mind - the spirit of fun, and even the sense of humor.

Not to say that the Olympiad was not serious business, not at all. In fact, I would say it was some of the hardest tests that I ever took, and I am more proud of my performances in the CMO than in any other math contest. But it was always a pleasure to work on the problems. And I would continue thinking about the ones that I hadn't gotten all week, and then come back for the award ceremony to see the answers revealed. In hindsight, Soifer's presentations at the award ceremony feel like some of the first real math lectures I ever saw. They were so far beyond what they were teaching us in school, so different in style, yet somehow accessible at the same time. It felt like he was giving us a peek of an entire other world that we had never been exposed to.

I grew up to become a mathematician, but my road was a little bit of a long and winding one. In short, I was always much more excited about mathematics itself than I ever was about school, so much so that I barely made it out of high school and dropped out of college twice. But after a few false starts I set my sights on getting a math Ph.D., which I finished at the University of Washington in 2007. Since then, I've been a postdoctoral fellow at Stanford University. I greatly enjoy both research and teaching, and I hope to find a tenure track job as a professor that will allow me to continue both. I think the Olympiad influenced me in many ways. It introduced me to the idea that there are many more math problems unsolved than there are solved. (I remember Professor Soifer saying, "To nearest percent, $0 \%$ of all math problems are solved."). It helped me find out that I am capable of obsessing about math problems for hours, or days, or longer. (Needless to say, this is an important trait for a math researcher.) And that which problems we work on, and how we work on them, is not only a matter of ability, but of aesthetics and taste. (The CMO awarded special prizes for creative solutions, as well as literary prizes for clever poems and stories.) I think it also helped me realize how much I enjoy just talking with people about math-some of the first 'serious' math conversations I remember having with Soifer.

I appreciate that Sasha treated me as a friend and a peer even when he first met me as a 14-year-old, and I have stayed in touch with him and connected to the Olympiad since then. I have contributed three research articles so far to his journal Geombinatorics, and helped judge the CMO several times. I was honored to be able to help judge for the 25th annual CMO 
last year. I think Sasha and I are just kindred spirits. We may naturally have some similar tastes mathematically, but I also think we recognized and appreciated the mischief and humor in each other's eyes from when we first met. For some reason, right now I am remembering winning the Olympiad, and shaking hands with Professor Soifer and one of the deans, and Soifer turning to the dean and saying, "See! This is why we should admit C-students!"

The $\mathrm{C}$ student eventually grew up. He received his Ph.D. from University of Washington in 2007 . He completed postdoctoral fellowships at Stanford and the Institute for Advanced Study [Princeton], and then proceeded to a tenure-track position at Ohio State University. Since then, he was awarded an Alfred P. Sloan Research Fellowship and an NSF CAREER award, and was awarded tenure in 2015.

Now, back to Matthew's CMO reminiscences.

It was exciting to visit the 30th CMO in 2013. It was wonderful to spend a week back in my childhood home of Colorado, visiting with my mom and stepdad in Colorado Springs, seeing old friends around the state, and driving around in the mountains. The week began and ended with the Olympiad.

First, it was a day and a half of grading exams with Sasha and a panel of about 20 judges. I am surprised hearing myself to say that it was fun, because grading calculus exams is usually boring if not depressing. In the $\mathrm{CMO}$ you sometimes have to read for a while to find the diamond in the rough, but it is always a pleasure being surprised by essays with unexpected proofs, or even papers with no proofs but funny poetry or well-drawn art. The week ended with the award ceremony. The presentation of awards was preceded by a panel discussion with Sasha and several former judges and participants from the Olympiad including myself. It was wonderful to hear many shared memories, and to see some of the former Olympians grown up. David Hunter, who came a few years ahead of me, is now a statistics professor at Penn State. It seemed parallel to my own career trajectory as a math professor at Ohio State. It was impossible not to speculate about the impact that the Olympiad had had on us. The CMO gave encouragement to both of us growing up, and I am sure helped us both to find our confidence and passion.

I found what I enjoyed most about that week in Colorado and reconnecting with the Olympiad: it was the people. It was wonderful to reminisce and reflect with several former winners of the Olympiad including David Hunter, Mark Heim, and Russel Shaffer. I enjoyed catching up with Bob Ewell and Jerry Klemm, who have probably judged more than fifty CMO's between the two of them. This leads to my final observation. The Colorado Math- ematical Olympiad is mathematics; it is sport; it is art. And it is also community. There is a spirit of friendship and inclusion-people with shared vision and inspiration, enjoying each other's company and quirkiness. I believe we are slowly creating a culture where young people can discover their inherent intelligence and creativity. It is much too soon to know the long-term impacts of the CMO.

\subsection{Movement 2. "I've begun paying off my debt with new kids" by Aaron Parsons, Professor of Astronomy, University of California Berkeley}

Permit me first reproduce a section about Aaron Parsons from my Olympiad book (Soifer, 2011).

The best teachers are usually found in major metropolitan centers, where schools are well funded and cared for by enlightened populus. The small town of Rangely in the very northwestern corner of the state of Colorado near the Colorado-Utah border did not hold promise of mathematical inspiration for their small student body-unless a miracle were to happen. It did! The miracle's name was Melvin Oliver, a mathematics teacher at Rangely High School.

Mel must have practiced magic, for nearly all students he brought to the Colorado Mathematical Olympiad over many years, won various awards. (We typically presented awards to no more than $20 \%$ of contestants.) In most years, Melvin Oliver and his students traveled twice to Colorado Springs (a 13-h round trip by car), to attend both the Olympiad and a week later the Award Presentation. Among the many of Mel's fine Olympians, one stood out: Aaron Parsons, who won a Silver Medal as a junior in 1997, and a Gold Medal in 1998. All this Aaron achieved while successfully competing in track and field - sprint to be precise — on the state' highest level, placing 3rd in Colorado. And Aaron was rewarded by an improbable journey, from the town of Rangely to Harvard University as a mathematics major!

When invited to Harvard, Aaron shared the good news with me in his July 25, 1998, letter:

Dear Professor Soifer,

I would first like to say that I have enjoyed your contest throughout my high school years. It is one of the few contests in Colorado that places all students on an equal level and allows each to test his/her merit through problem-solving skills and critical thinking. This contest, to me, comes closer to capturing the essence of mathematics than any other contest I have ever taken. Thank you very much for putting together such a remarkable contest for so many years.

I would also like to thank you for helping provide for my college education by offering scholarships to the winners of the contest. I have been accepted to Harvard 
University, and will pursue a degree in mathematics and physics there this coming year...

Thank you again for your wonderful math contest. I am sure you will be seeing a lot more of my favorite teacher, Mel Oliver, and the Rangely Math Club.

Success had no effect on this modest, talented, cheerful young man. Ten years passed. I contacted Aaron in December 2008 and asked him to share his experiences during and after the Olympiad. On December 11, 2008 Aaron replied:

Dear Prof. Soifer,

How wonderful to hear from you! Sorry that I've been slow to return the message you left on my guestbook (I only check it infrequently). I would be more than happy to provide a short note about myself and CMO:

I participated in the Colorado Math Olympiad [CMO] from 1994 to 1998, representing Rangely High School [RHS] and coached by the generous and committed Melvin Oliver, who single-handedly developed and supported the math program at RHS. At a time when most math contests focused on speed, numbers, and arithmetic tricks, CMO stood out as something completely different.

The first time I took a CMO test, I was flabbergasted-I was so tuned to the 'other' type of contest, I felt I could hardly solve a single problem! No one on our team qualified for the awards ceremony that year, and one of the problems just drove me nutsone about polygons of unit area on a grid. Resolving to qualify for the 'answer session' next year, I set to work. I did manage an 'Honorable Mention' the next year, and after visiting UCCS and meeting Prof. Soifer for the annual recapitulation of the contest, both Mel and I came away with a new understanding of a broader, more abstract, and altogether much more fun side of mathematics than we had previously seen. I distinctly remember the following year, when, having qualified for the awards ceremony, I found myself unfortunately needing to skip the ceremony in order to participate in a state track meet (held just an hour away). I met with Prof. Soifer to excuse myself and to apologize for necessity of my departure. "Oh, that's quite alright," he said. "You know, I was a sprinter myself in high school." And a good one at that, as I found out. I began to understand his bounding energy in front of his students, to guess at a joie d' vivre that could be expressed both academically and athletically.

After graduating from high school, I studied physics and mathematics (and ran track) at Harvard. There, I discovered that math-the real math that mathematicians do-was really much more like the bounding, gleeful CMO math than any other math I had been exposed to. I grew much better versed in mathematical reasoning, but it still wasn't until my second year away at college that the solution to that demonic polygon problem finally came to me. Liberated at long last, I moved on to astrophysics. I am currently finishing my doctorate at [the University of California] Berkeley, working to discover the first stars that formed in the universe 10 billion years ago.

Aaron Parsons

I asked Aaron to update us on his life's events that happened since 2010. On August 27, 2016, Aaron wrote:

Dear Alexander,

A decade later, I must again beg your forgiveness for being slow to respond. I suppose this reveals one of my fundamental character flaws. None of us are perfect, but please accept my apologies.

Many things have happened since we last talked! I'm still at Berkeley, but now as a professor (tenured just last month) with three wonderful children. Teaching, research, and parenting suit me very well. I tell my students that if they are lucky, they will find a job where they enjoy the idea of what they are working on (the big picture) and the actual work (the details). I love the math, engineering, and social interaction that comes with running a scientific experiment, and what could be more interesting than mapping the universe as it appeared 10 billion years ago?

One of my great pleasures is sharing with students and children the fun, intricate, and often surprising worlds of math and science. Inspired by the CMO and by Rangely's math heroes Mel and Lorraine Oliver, I started up a Family Math Night at our local elementary school. This last year, we learned about fractals and functions, Mobius strips and curved space, spirals and tessellations. Parents are skeptical that these subjects are 'math'. Little do they know that this math is more math than the math they think math is!

Thinking back to our high school trips to participate in the CMO, I'm indebted to you and Mel for teaching me 'real' math. As I've begun paying off my debt with new kids, I' $m$ finally beginning to understand why Mel was willing to drive a van with ridiculously loud teenagers 12 hours across the state of Colorado, just to participate in Dr. Soifer's Colorado Math Olympiad.

All the best,

Aaron 


\subsection{Movement 3: "Aesthetic of Personal Mastery" by Hannah Alpert, Professor of Mathematics, University of British Columbia}

Hannah Alpert was the first girl to win back to back second prizes in the Colorado Mathematical Olympiad in 2006 and 2007. Moreover, she was a solo second prize winner behind only Sam Elders, who was a solo first prize winner. Before that, as a sophomore in 2005, Hannah won third prize, and was, together with the winner Mark Heim, the only Olympian to solve problem 22.4, in her own way which was unknown to me.

As an undergraduate mathematics major at the prestigious University of Chicago, Hannah Alpert received a number of awards, including "the 2010 Alice T. Schafer Prize for excellence in mathematics by an undergraduate woman." The following year, she won a National Science Foundation Research Fellowship, entered a Ph.D. program in mathematics at the Massachusetts Institute of Technology (MIT), and in April 2016 defended her doctoral thesis entitled "Special gradient trajectories counted by simplex straightening".

I have been meeting, with great pleasure, Hannah's talented family at the Award Presentations for many years. Her father, Dr. Bradley Alpert, has been a scientist at the National Institute of Standards and Technology in Boulder. Hannah's mother, Silva Chang, has run a mathematical circle in Boulder, which produced many of our Olympiad's winners. Hanna's younger brother, Ben Alpert, won fourth prize in 2009, third prizes in 2008 and 2010, and finally first prize in 2011.

On May 23, 2016, Hannah proved a theorem about smallness of our world, by sharing with me her mathematical interaction with our 1990 and 1991 Olympiad winner Matthew Kahle:

It turns out that one of the main people I expect to work with next is Matt Kahle. I will be a postdoc at ICERM [Mathematics Research Institute at Brown University] during the Topology in Motion program that he is helping to organize-ICERM is sponsoring me for the whole year-and then I have a 3-year position at Ohio State. It was funny one day when my mom and I realized that we had each mentioned him on that same day (she had read about him in your books) but hadn't realized we were talking about the same person. He is a friend of my [MIT] advisor Larry Guth so Larry had given me a project to work on that he'd gotten from Matt.
Hannah has an original style, all her own, and includes imagery in mathematics. Hannah's success was easy to predict, but she exceeded all expectations. On August 25, 2016, Hannah wrote the following essay especially for the book from which we are taking excerpts.

The first time I went to the CMO, I went with a group of students from my high school. I didn't know them, so I assumed that they were the real math experts. I didn't realize that, having attended an intensive summer math program, I had more math training than they did. Out of the five problems on the test, I thought I had done about one and a half, plus the first one which was easy. It seemed like an appropriate level of performance for someone who didn't normally do this kind of thing. The other students were saying they'd solved three or four problems, which I assumed was more typical.

We were all invited to the award ceremony, but there had been a big snowstorm, so the drive that would normally already take multiple hours was going to be much slower. My family decided we wouldn't go, because presumably I wasn't winning a very substantial award anyway. We were quite surprised to hear afterward that I had won third place, better than those 'real math experts' from my school!

I remember other things from other years. It was always funny to me that there would be so many contestants that we filled up several rooms all sitting right next to each other, but then most people would leave after half an hour. You might think this would work out fine and the serious contestants would get plenty of space, except that I knew most of them by this time, so we would arrive together and sit together, spending the whole test all clumped up and trying not to look at each other's papers. We were too awkward to just stand up and move to an empty table while the test was in progress-what if a proctor wouldn't let us finish, or a friend was offended? So I remember that one year in the last hour of the test, my friend next to me must have been getting stuck on the math, because she took out a hairbrush and started brushing her hair. I was laughing to myself while trying to make sure that we didn't look like we were communicating so that we didn't get kicked out for cheating.

I also remember that one of my solutions showed up in the award ceremony. It was a graph theory problem-I just looked it up and it's number 5, 'Math Party', from 2006 - and the problem was stated in terms of mathematicians sitting around a table according to their col- 
laboration distance. My solution was stated in terms of a completely different story, something about an ant crawling around in the desert and needing to stop every so often to eat or drink or refuel or something. I think the graders found this amusing. At the time I thought that explaining a proof meant that I was supposed to describe everything that was happening in my head, so if I was seeing all kinds of gestures and colors, then that's what should be communicated. It took me a few years to understand that each person has to build a separate understanding, and you can't just import it all in one piece from one mind to another.

I like to refer to the books of old CMO problems whenever I want some stand-alone problems to get people talking. It's impressive that Professor Soifer and his writing teams have collected such a large number of problems that are prerequisite-free, immediately engaging, and at just the right level of requiring some thought but still being solvable without obscure trickery. These problems are so convenient when I am teaching and need to help a group of students to get to know each other mathematically, to hear each person's thinking style and feel out the shape of a collaboration. I think what resonates with me most about the CMO is what I'll call the 'aesthetic of personal mastery'. After high school I went to college at the University of Chicago, where they trained me in a large body of standard mathematical knowledge. Then I went to grad school at MIT, where I continued to try to learn all the words and basic concepts so that I might understand what everybody was talking about. It's been in the past year, finishing my Ph.D., that I've found my way back to this aesthetic of personal mastery and realized that I had it in high school and then lost it in college. In the CMO problems, you aren't judged on how completely you have assimilated the wisdom of the ages. You can just think about the problem yourself. You can do it in the way that makes sense to you, using the tools you already know. This is what I mean by the aesthetic of personal mastery.

There are six published papers on research I did before entering grad school. I've just submitted the fourth paper on research I did during grad school. I think that what has distinguished each project is my ability to move away from community expectations for what I ought to understand-in undergrad this meant leaving campus to go to REU programs - and spend time with what I could understand by myself. I guess with all those research papers it sounds like I kept the aesthetic of personal mastery all along. I sort of did without realizing it. I thought I was really supposed to be learn- ing all this other stuff-I'm not saying it hasn't been useful, though! — and these research projects were side amusements while I learned to do things properly. Now I'm more intentional about making space to do things my way.

Just like how the CMO focuses on helping students develop the skills of exploring mathematics rather than on specific mathematical content, I remain most interested in how to work, learn, and think, regardless of the topic of study. I'm not set on being a professor, but I do plan to have academic jobs for the next few years. I expect that my orientation toward mental processes will help me in my teaching. In research, I intend to take on any projects where I can find something to understand thoroughly, whether or not it all adds up to a cohesive mathematical research program.

\section{Part VI. Summing-up}

This essay has acquainted you with goals of the Soifer (formerly Colorado) Mathematical Olympiad and some of its many bridges to 'real' mathematics. You have read beautifully written memoirs of some of the Olympiad's winners, who credited the Olympiad with influencing their lives. What about thousands of other Olympians, who did not win top prizes, what was their profit? In March 1988, the legendary Paul Erdős stayed with me as we worked on creating and solving research problems. I posed to him this very question. Paul replied: "The Olympiads are important because they bring a new enthusiasm" to young mathematicians. Indeed, I experienced that the other day, on April 23, 2021.

Due to the corona virus epidemic, we had to postpone the 37th Olympiad three times: from April 2020 to August 2020, to April 23, 2021, and now to October 1, 2021. Young middle and high school mathematicians of Windsor Charter Academy, located near Denver, Colorado, did not want to wait for Olympic fun any longer. And so, on April 23, 2021, a bus-full of students and their mathematics teachers traveled to Colorado Springs for my lecture on Olympiad problems, including the problem addressing another epidemic, the one of Ebola virus. Their shining eyes conveyed the enthusiasm Paul Erdős spoke about. Their questions showed a depth of understanding and love for mathematics. This is what the Olympiads are all about.

The 37th Soifer Mathematical Olympiad finally took place on October 1, 2021. My next Olympiad book will include its problems and solutions, and Further Explorations inspired by the Olympiad problems of the Fourth Decade. 
Acknowledgements I am deeply grateful to Professor Dr. Gabriele Kaiser for encouraging my writing of this essay and for her valuable suggestions. I thank Professor Emeritus Dr. Norma C. Presmeg for proofreading the manuscript and kindly advising me on the stylistic conventions.

\section{References}

Agahanov, N. H., et al. (2007). Vserossijskie olimpiady shkol'nikov po matematike 1993-2005. MZNMO.

Fedorov, R. M., et al. (2006). Moskovskie Matematicheskie olimpiady, Prosveshhenie, Moscow 1993-2005. MZNMO.

Gal'perin, G. A., \& Tolpygo, A. K. (1986). Moskovskie Matematicheskie olimpiady. Prosveshhenie.

Kahle, M., Martinez Figueroa, F., \& Soifer, A. (2020). A square grid coloring problem. Geombinatorics, XXIX(4), 167-184.

Leman, A. A. (1965). Sbornik zadach moskovskikh matematicheskikh olimpiad. Prosveshhenie.

Shklarsky, D. O., Chentzov, N. N., \& Yaglom, I. M. (1994). The USSR Olympiad problem book. Dover Publications.
Soifer, A. (1994). Colorado Mathematical Olympiad: The first ten years and further explorations. Center for Excellence in Mathematical Education.

Soifer, A. (2011). The Colorado Mathematical Olympiad and further explorations: From the mountains of Colorado to the peaks of mathematics. Springer.

Soifer, A. (2017). The Colorado Mathematical Olympiad, the third decade and further explorations: From the mountains of Colorado to the peaks of mathematics. Springer.

Tolpygo, A. G. (2010). Tysyacha zadazh mezhdunarodnogo matematicheskogo Turnira gorodov (Thousand problems of the International Tournament of Towns). MZNMO.

Vasiliev, N. B., \& Egorov, A. A. (1988). Zadachi vsesojuznyh matematicheskih olimpiad (Problems of the Soviet Union Mathematical Olympiads). Nauka.

Publisher's Note Springer Nature remains neutral with regard to jurisdictional claims in published maps and institutional affiliations. 